\title{
High seroprevalence of Toxoplasma gondii infection in a subset of Mexican patients with work accidents and low socioeconomic status
}

\author{
Cosme Alvarado-Esquivel ${ }^{1 *}$, Alejandro Torres-Castorena ${ }^{2}$, Oliver Liesenfeld ${ }^{3}$, Sergio Estrada-Martínez ${ }^{4}$ and \\ Jesús D Urbina-Álvarez²
}

\begin{abstract}
Background: Toxoplasma gondii has been associated with reflex impairment and traffic accidents. It is unknown whether Toxoplasma infection might be associated with work accidents. Therefore, using a case-control seroprevalence study design, 133 patients with a recent work accident and 266 control subjects of the general population from the same region were examined with enzyme-linked immunoassays for the presence and levels of anti-Toxoplasma lgG antibodies and anti-Toxoplasma IgM antibodies. Socio-demographic, work, clinical and behavioral characteristics from each worker were obtained.
\end{abstract}

Results: Eleven (8.3\%) of 133 patients, and 14 (5.3\%) of 266 controls had anti-T. gondii IgG antibodies. Anti-T. gondil IgG levels were higher than $150 \mathrm{IU} / \mathrm{ml}$ in $8(6 \%)$ patients and $10(3.8 \%)$ controls. Anti-T. gondii IgM antibodies were found in one $(0.8 \%)$ of the workers, and in $6(2.3 \%)$ of the controls. No statistically significant differences in the $\lg G$ seroprevalences, frequencies of high IgG levels, and IgM seroprevalences among patients and controls were found. In contrast, a low socio-economic level in patients with work accidents was associated with Toxoplasma seropositivity $(P=0.01)$. Patients with work accidents and low socioeconomic status showed a significantly $(\mathrm{OR}=$ 3.38; $95 \% \mathrm{Cl}: 0.84-16.06 ; P=0.04$ ) higher seroprevalence of $T$. gondii infection than controls of the same socioeconomic status ( $15.1 \%$ vs. $5 \%$, respectively). Multivariate analysis showed a positive association of $T$. gondii infection with boar meat consumption ( $\mathrm{OR}=3.04 ; 95 \% \mathrm{Cl}: 1.03-8.94 ; P=0.04)$. In contrast, a negative association between $T$. gondii infection and national trips ( $\mathrm{OR}=0.40 ; 95 \% \mathrm{Cl}$ : $0.17-0.96 ; P=0.04)$, sausage consumption $(\mathrm{OR}=$ $0.20 ; 95 \% \mathrm{Cl}: 0.05-0.68 ; P=0.01)$, and ham consumption $(\mathrm{OR}=0.16 ; 95 \% \mathrm{Cl}: 0.05-0.51 ; P=0.002)$ was found.

Conclusions: In the study described here seropositivity to $T$. gondii was associated to work accidents in a subset of patients with low socioeconomic status. This is the first report of an association of T. gondii infection and work accidents. Further studies to confirm our results are needed. Results may help in designing optimal prevention strategies to avoid T. gondii infection.

Keywords: Toxoplasma gondii, seroprevalence, work accidents, case-control study, epidemiology

\section{Background}

The parasite Toxoplasma gondii (T. gondii) infects humans and animals worldwide [1]. Major routes of infection with $T$. gondii include eating undercooked or raw meat containing tissue cysts, and ingesting food or water contaminated with oocysts $[1,2]$. The clinical

\footnotetext{
* Correspondence: alvaradocosme@yahoo.com

'Faculty of Medicine and Nutrition, Juárez University of Durango State.

Avenida Universidad S/N. 34000 Durango, Dgo, Mexico

Full list of author information is available at the end of the article
}

spectrum of infection with $T$. gondii in humans varies from asymptomatic latent infection to severe disease affecting eyes, lymph nodes and central nervous system $[1,2]$. Infection with $T$. gondii has been linked to traffic accidents. Fukunaga et al. [3] reported a rare case of brain calcification supposedly caused by infection with $T$. gondii in a man that had a fatal traffic accident. Gyori et al. [4] reported an unusual case of cerebral toxoplasmosis leading to a fatal vehicular crash. In retrospective case-control studies, Flegr et al. [5], Yereli et al.

\section{() Biomed Central}


[6], and Kocazeybek et al. [7] found significantly higher seroprevalences of $T$. gondii infection in subjects with traffic accidents than those in control groups. The increased risk of traffic accidents in Toxoplasmainfected subjects was confirmed in a prospective cohort study [8]. These results and the fact that $T$. gondii may cause visual $[1,2]$ and reflex impairments $[9,10]$ in humans, and changes in behavior in rodents [11] and humans [12] lead us to raise the question whether $T$. gondii infection is linked to work accidents too. Since there is no information about the association of $T$. gondii infection with work accidents we used a matched seroprevalence case control study to determine the association of $T$. gondii seropositivity and anti- $T$. gondii IgG levels with work accidents. In addition, we investigated socio-demographic, work, clinical, and behavioral characteristics associated with $T$. gondii seropositivity.

\section{Methods}

\section{Study design and study populations}

Through a case-control seroprevalence study, 133 patients with a recent work accident and 266 control subjects of the general population from the same region were examined with enzyme-linked immunoassays for the presence and levels of anti-Toxoplasma IgG antibodies and for the presence of anti-Toxoplasma IgM antibodies. This study was performed from January 2009 to December 2010 in workers attending the Department of Occupational Medicine in a public hospital (Mexican Social Security Institute) in Durango City, Mexico. Inclusion criteria for cases were: 1) to have had a recent work accident regardless its severity; 2) aged 17 years and older; 3 ) any gender; and 4) who accepted to participate in the study. As a strategy for recruiting workers we invited them when seeking medical consultation and incapacity in the Department of Occupational Medicine. Of 160 patients invited, 133 (83.1\%) agreed to participate in the study. All patients resided in Durango. Eighty one patients were male and 52 were female. The mean age of the patients was $33.75 \pm 11.04$ years (range: $17-60$ years). The control group consisted of 266 subjects drawn from the general population of Durango City and matched with cases by age, gender, and residence. The mean age in controls was $33.36 \pm 11.03$ (range: 17-60) and did not differ significantly from that of patients with a recent work accident $(P=0.99)$.

\section{Ethical aspects}

This study was approved by the Institutional Ethical Committee of the Mexican Social Security Institute. The purpose and procedures of the study were explained to all participants, and a written informed consent was obtained from all of them.
Socio-demographic, clinical, work, and behavioral data

We explored the characteristics of the participants with the aid of a standardized questionnaire. Socio-demographic data including age, gender, occupation, birth place, residence, educational level and socioeconomic status were included in the analysis. Work data included seniority (number of years) in the work place, type of accident (falls, slipping, trips), cause of accident, type of injury, work shift, time of day the accident happened, history of alcohol or drug consumption just before the accident, and number of previous work accidents in life. Contributing and confounding risk factors of behavioral data from all participants were also obtained. These factors included animal contacts, presence of cats at home or in the neighborhood, cleaning cat feces, travelling in Mexico and abroad, meat consumption (pork, beef, goat, sheep, boar, chicken, turkey, rabbit, venison, squirrel, horse, or other), degree of meat cooking, consumption of unpasteurised milk, dried or cured meat (ham, sausages, salami, chorizo, or dried beef), unwashed raw vegetables, fruits, or untreated water, frequency of eating out of home (in restaurants or fast food outlets), and contact with soil (gardening or agriculture). Questions regarding contributing and confounding risk factors of behavioral data from all participants refer to ever during life. Clinical data included presence of underlying disease, history of blood transfusion or transplant, and memory, reflex, hearing, and visual impairments.

\section{Laboratory tests}

Serum samples were obtained from all participants and kept frozen at $-20^{\circ} \mathrm{C}$ until analyzed. Serum samples were assayed by qualitative and quantitative methods for antiT. gondii IgG antibodies with a commercially available enzyme immunoassay: "Toxoplasma IgG" kit (International Immuno-Diagnostics, Foster City, California). Anti- $T$. gondii IgG antibody levels were expressed as International Units (IU) per $\mathrm{ml}$, and a result equal to or greater than $8 \mathrm{IU} / \mathrm{ml}$ was considered positive. In addition, sera positive for $T$. gondii IgG were further tested for anti-T. gondii IgM antibodies by a commercially available enzyme immunoassay: "Toxoplasma IgM" kit (International Immuno-Diagnostics, Foster City, California). All tests were performed following the instructions of the manufacturer.

\section{Statistical Analysis}

Results were analyzed with the aid of the software Epi Info version 3.5.1 and SPSS 15.0 (SPSS Inc. Chicago, Illinois). Age among the groups was compared by the student's $t$ test. For comparison of the frequencies among the groups, the Yates corrected test and when indicated the Fisher exact test with 1 -tailed $P$ value and exact confidence limits were used. Bivariate and multivariate 
analyses were used to evaluate the association between the characteristics of the subjects and T. gondii infection. The association of $T$. gondii infection with work accidents was assessed by comparing the seroprevalences of anti- $T$. gondii IgG antibodies in patients with work accidents and controls. In addition, the association of $T$. gondii infection with specific accidents (falls, slipping, trips) was assessed by comparing the seroprevalences of anti- $T$. gondii IgG antibodies in patients with and patients without a specific accident. Seropositivity to IgG or IgM was analyzed with dichotomous data. Variables were included in the multivariate analysis if they had a $P$ value equal to or less than 0.20 in the bivariate analysis. Age-adjusted odd ratio (OR) and 95\% confidence interval $(\mathrm{CI})$ were calculated by multivariate analysis using multiple, unconditional, logistic regression. A $P$ value less than 0.05 was considered statistically significant.

\section{Results}

Eleven (8.3\%) of the 133 patients, and 14 (5.3\%) of the 266 controls were positive for anti-T. gondii IgG antibodies $(\mathrm{OR}=1.62 ; 95 \%$ CI: $0.71-3.68 ; P=0.17)$. Anti- $T$. gondii IgG levels were higher than $150 \mathrm{IU} / \mathrm{ml}$ in $8(6 \%)$ patients and $10(3.8 \%)$ controls $(\mathrm{OR}=1.63 ; 95 \% \mathrm{CI}$ : $0.63-4.25 ; P=0.21$ ) (Figure 1). Anti-T. gondii IgM antibodies were found in one $(0.8 \%)$ of the patients, and in $6(2.3 \%)$ of the controls $(\mathrm{OR}=0.45 ; 95 \%$ CI: $0.07-2.71$; $P=0.26)$.
General socio-demographic characteristics of subjects with work accidents are shown in Table 1 . Of the sociodemographic characteristics, only a low socio-economic level was associated with Toxoplasma seropositivity (OR $=5.71 ; 95 \%$ CI: $1.33-24.54 ; P=0.01)$. Patients with work accidents and low socioeconomic level showed a significantly $(\mathrm{OR}=3.38 ; 95 \% \mathrm{CI}: 0.84-16.06 ; P=0.04)$ higher seroprevalence $(8 / 53: 15.1 \%)$ of $T$. gondii infection than control subjects (4/80: $5.0 \%)$ of the same socioeconomic level.

Bivariate analysis of $T$. gondii infection and work characteristics including seniority in the work, type of accident, cause of accident, type of injury, work shift, time of day the accident happened, history of alcohol or drug consumption just before the accident, and number of previous work accidents in life did not show any statistically significant association.

Clinical characteristics as evidence for the presence of underlying disease, history of blood transfusion or transplant, memory, reflex, hearing, and visual impairments did not show any association with Toxoplasma seropositivity.

Behavioral characteristics with a $P$ value equal to or less than 0.20 in the bivariate analysis included the presence of cats at home, raising animals, travelling in Mexico and abroad, consumption of goat, boar, and turkey meats, consumption of raw meat, unpasteurized goat milk, unwashed raw vegetables, sausages, ham, salami and untreated water; eating out of home, and soil

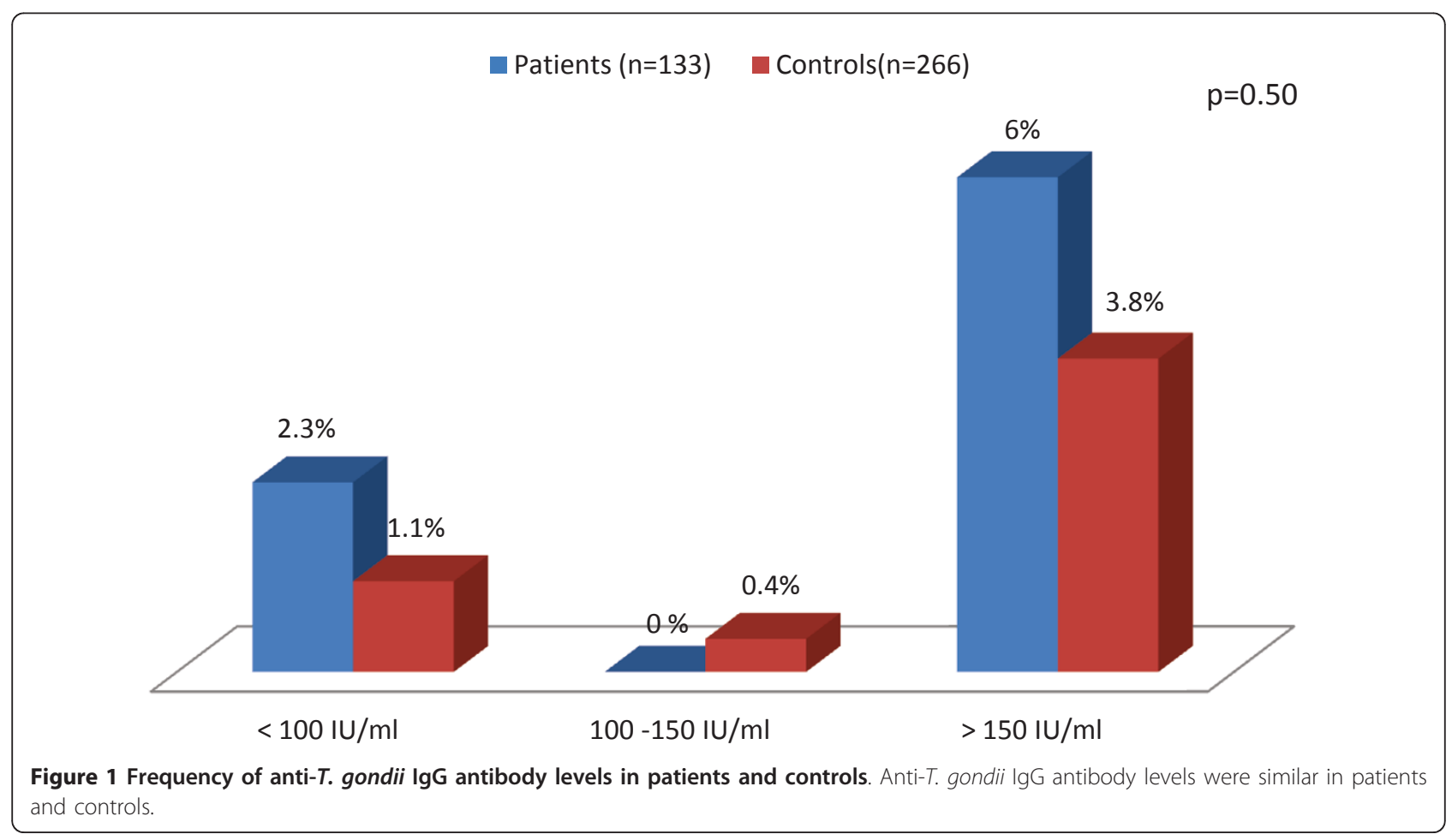


Table 1 Socio-demographic characteristics of patients with work accidents and their association with Toxoplasma infection.

\begin{tabular}{|c|c|c|c|c|c|}
\hline \multirow[b]{2}{*}{ Characteristic } & \multirow[b]{2}{*}{ No. } & \multirow[b]{2}{*}{$\%$} & \multicolumn{2}{|c|}{$\begin{array}{c}\text { Prevalence of } \\
\text { T. gondii infection }\end{array}$} & \multirow[b]{2}{*}{$P$ value } \\
\hline & & & No. & $\%$ & \\
\hline \multicolumn{6}{|l|}{ Age groups (years) } \\
\hline 30 or less & 60 & 45.1 & 3 & 5 & 0.37 \\
\hline $31-50$ & 60 & 45.1 & 6 & 10 & \\
\hline $51-70$ & 13 & 9.8 & 2 & 15.4 & \\
\hline \multicolumn{6}{|l|}{ Gender } \\
\hline Male & 81 & 60.9 & 9 & 11.1 & 0.2 \\
\hline Female & 52 & 39.1 & 2 & 3.8 & \\
\hline \multicolumn{6}{|l|}{ Occupation } \\
\hline Construction & 7 & 5.3 & 2 & 28.6 & 0.48 \\
\hline Carpenter & 3 & 2.3 & 0 & 0 & \\
\hline Driver & 9 & 6.8 & 0 & 0 & \\
\hline Electrician & 1 & 0.8 & 0 & 0 & \\
\hline Employee & 62 & 46.6 & 3 & 4.8 & \\
\hline Cattle raising & 1 & 0.8 & 0 & 0 & \\
\hline Smith & 1 & 0.8 & 0 & 0 & \\
\hline Cleaning & 5 & 3.8 & 0 & 0 & \\
\hline Machinist & 5 & 3.8 & 1 & 20 & \\
\hline Factory worker & 7 & 5.3 & 2 & 28.6 & \\
\hline Machine operator & 1 & 0.8 & 0 & 0 & \\
\hline Professional & 1 & 0.8 & 0 & 0 & \\
\hline Other & 30 & 22.6 & 3 & 10 & \\
\hline \multicolumn{6}{|l|}{ Residence area } \\
\hline Urban & 124 & 93.2 & 9 & 7.3 & 0.2 \\
\hline Suburban & 3 & 2.3 & 1 & 33.3 & \\
\hline Rural & 6 & 4.5 & 1 & 16.7 & \\
\hline \multicolumn{6}{|l|}{ Educational level } \\
\hline No education & 6 & 4.5 & 2 & 33.3 & 0.07 \\
\hline $1-12$ years & 127 & 95.5 & 9 & 7.1 & \\
\hline \multicolumn{6}{|l|}{ Socio-economic level } \\
\hline Low & 53 & 39.8 & 8 & 15.1 & 0.01 \\
\hline Medium & 78 & 58.6 & 2 & 2.6 & \\
\hline
\end{tabular}

floors at home. Multivariate analysis of these characteristics showed a positive association of $T$. gondii infection with boar meat consumption (OR $=3.04$; $95 \%$ CI: 1.03 8.94; $P=0.04$ ), and a negative association of $T$. gondii infection with national trips $(\mathrm{OR}=0.40$; $95 \% \mathrm{CI}$ : 0.17 $0.96 ; P=0.04)$, sausage consumption $(\mathrm{OR}=0.20 ; 95 \%$ CI: $0.05-0.68 ; P=0.01)$, and ham consumption $(\mathrm{OR}=$ 0.16; 95\% CI: $0.05-0.51 ; P=0.002$ ) (Table 2).

\section{Discussion}

We found comparable seroprevalences of both anti- $T$. gondii IgG and IgM antibodies, and comparable frequencies of anti- $T$. gondii IgG levels higher than 150 $\mathrm{IU} / \mathrm{ml}$ in patients suffering from a recent work accident and controls. However, a subset of workers with work
Table 2 Multivariate analysis of selected characteristics of participants and their association with Toxoplasma gondii infection.

\begin{tabular}{lccc}
\hline Characteristic & $\begin{array}{c}\text { Age- } \\
\text { adjusted } \\
\text { Odds ratio }\end{array}$ & $\begin{array}{c}\text { 95\% } \\
\text { confidence } \\
\text { interval }\end{array}$ & value \\
\hline Cats at home & 1.46 & $0.64-3.33$ & 0.35 \\
Raising animals & 1.55 & $0.56-4.28$ & 0.39 \\
Travel abroad & 0.47 & $0.17-1.32$ & 0.15 \\
National trips & 0.40 & $0.17-0.96$ & 0.04 \\
Goat meat consumption & 1.96 & $0.85-4.52$ & 0.11 \\
Boar meat consumption & 3.04 & $1.03-8.94$ & 0.04 \\
Turkey meat consumption & 0.67 & $0.29-1.56$ & 0.36 \\
Raw meat consumption & 5.00 & $0.45-55.4$ & 0.19 \\
Raw goat milk consumption & 2.77 & $0.72-10.57$ & 0.13 \\
Sausage consumption & 0.20 & $0.05-0.68$ & 0.01 \\
Ham consumption & 0.16 & $0.05-0.51$ & 0.002 \\
Salami consumption & 0.40 & $0.15-1.05$ & 0.06 \\
Unwashed raw vegetables & 0.45 & $0.13-1.56$ & 0.20 \\
Untreated water & 2.35 & $0.91-6.08$ & 0.07 \\
consumption & & $0.18-1.87$ & 0.37 \\
Eating out of home & 2.11 & $0.66-6.7$ & 0.20 \\
Soil floors at home & & &
\end{tabular}

accidents and low socioeconomic level showed a significantly higher seroprevalence of $T$. gondii infection than control subjects of the same socioeconomic level. These results suggest that in general, $T$. gondii infection seems not be associated with work accidents in the population of Mexican workers from Durango; but in particular, suggest that $T$. gondii infection might be a contributing factor for work accidents in workers with low socioeconomic status. In principle, $T$. gondii may affect senses important to avoid any kind of accidents namely vision and hearing. It is well known that infections with $T$. gondii may lead to chorioretinitis $[1,2]$ thus affecting vision. Furthermore, infection with $T$. gondii has been linked to deafness [13] or hearing impairment [14]. Seroprevalence of $T$. gondii has been found higher in individuals with reflex $[9,10,15]$ and memory [16] impairments than those without these impairments. In the present study, we did not find an association of $T$. gondii infection with a specific impairment in patients with work accidents. This fact might explain the lack of association between $T$. gondii infection and work accidents in general.

Of the socio-demographic characteristics, a low socioeconomic status was associated with $T$. gondii infection in our patients. This result confirms that of a previous report in our region [17]. A low socioeconomic level may be linked to malnutrition, and this factor might impair the host defense against $T$. gondii infection. Therefore, it is likely that health could be more easily impacted by $T$. gondii in workers with low socioeconomic status than in 
workers with higher socioeconomic status. This is supported by the fact that health in Tepehuanos, one of the poorest populations in Durango, has been impacted by $T$. gondii infection. In a recent study in Tepehuanos, seropositivity to $T$. gondii was associated with frequent headaches and hearing impairment [14]. In addition, other factors might contribute to an increase in the likelihood of an accident in $T$. gondii seropositive subjects. Several reports indicate that $T$. gondii infection may affect the reaction time in infected individuals. Havlícek et al. [18] in a double blind study showed significantly longer reaction times of subjects with latent toxoplasmosis in comparison with those of controls. Moreover, those researchers found a positive correlation between length of infection and mean reaction time suggesting that slow and cumulative effects of latent toxoplasmosis rather than a one-step (and possible transient) effect of acute toxoplasmosis disease are responsible for the decrease of psychomotor performance of infected subjects. Novotná et al. [19] showed that heterozygous men with both the $\mathrm{RhD}$ plus and the RhD minus alleles were protected against prolongation of reaction times caused by infection with $T$. gondii. In a further study in men and women, Flegr et al. [20] confirmed that RhD-positive subjects were less sensitive to the influence of latent toxoplasmosis on reaction times than RhD-negative subjects. In the present study, Rh blood typing in patients and controls was not determined.

Behavioral/mental disorders in humans including schizophrenia, mood disorders, personality changes, and cognitive impairments may be related to infection with T. gondii $[12,21,22]$. In addition, experimental infection with $T$. gondii in rodents has caused changes in behavior including a loss in aversion to cat odor [11]. Behavioral/ mental changes induced by $T$. gondii might impair the work performance leading to work accidents.

With respect to behavioral characteristics, multivariate analysis showed a positive association of $T$. gondii infection with consumption of boar meat. Remarkably, in a previous independent study, we also found and association of boar meat consumption with $T$. gondii infection [23].

Our study has limitations. First, the sample size and power may not have been large enough to determine all risk factors and associations. Second, the type of accidents could be not severe enough to find further associations. The general population in Durango has shown low seroprevalence of $T$. gondii infection $[23,24]$ as compared with those in other Mexican states [24]. A low seroprevalence in Durango has been found even when using various kits detecting anti- $T$. gondii IgG antibodies. For instance, Velasco-Castrejón et al. [24] reported a $9.6 \%$ seroprevalence in population of Durango by an indirect immunofluorescence antibody test. Similarly, a $6.1 \%$ seroprevalence was found in pregnant women who attended a public hospital of Durango City by a microparticle enzyme immunoassay [25]. Therefore, the seroprevalences found in the present study by enzymelinked immunosorbent assay seem to be reliable. It is likely that the dry climate and high altitude in Durango may partially explain the low prevalence in Durango. Infection with $T$. gondii is more prevalent in low-lying areas than in mountainous areas and in humid areas than in dry areas [1].

\section{Conclusions}

In the study described here seropositivity to $T$. gondii was associated to work accidents in a subset of patients with low socioeconomic status. This is the first report of an association of $T$. gondii infection and work accidents. Further studies with a larger sample size will have to confirm the findings presented here. The identification of a behavioral characteristic associated with $T$. gondii seropositivity will help to design optimal preventive measures against $T$. gondii infection.

\section{Acknowledgements}

This study was supported by Fondos Mixtos Durango-Consejo Nacional de Ciencia y Tecnología, Mexico. Grant No. 66718.

\section{Author details}

'Faculty of Medicine and Nutrition, Juárez University of Durango State. Avenida Universidad S/N. 34000 Durango, Dgo, Mexico. ${ }^{2}$ Mexican Social Security Institute, Avenida Normal \# 200, 34000, Durango City, Durango, Mexico. ${ }^{3}$ Institute for Microbiology and Hygiene, Campus Benjamin Franklin, Charité Medical School, Hindenburgdamm 27. D-12203 Berlin, Germany. Present address: Roche Molecular Diagnostics, Pleasanton, CA. USA. ${ }^{4}$ Institute for Scientific Research, Juárez University of Durango State. Avenida Universidad S/N. 34000 Durango, Dgo. Mexico.

\section{Authors' contributions}

CAE conceived and designed the study protocol, participated in the coordination and management of the study, applied the questionnaires, performed the laboratory tests and data analysis, and wrote the manuscript. ATC and JDUA obtained clinical data, applied the questionnaires and performed the data analysis. SEM performed the statistical analysis. OL performed the data analysis, and wrote the manuscript. All authors read and approved the final version of the manuscript.

\section{Competing interests}

The authors declare that they have no competing interests.

Received: 8 October 2011 Accepted: 11 January 2012

Published: 11 January 2012

\section{References}

1. Dubey JP: Toxoplasmosis of animals and humans. Second edition. Boca Raton, Florida: CRC Press; 2010.

2. Montoya JG, Liesenfeld O: Toxoplasmosis. Lancet 2004, 363:1965-1976.

3. Fukunaga $T$, Fujiwara $S$, Ueno $Y$, Imabayashi T, Nakagawa $K$, Yanagida $Y$, Mizoi Y: Unusual calcification in brain suspected to be caused by toxoplasmosis: a report of an autopsy case. Nihon Hoigaku Zasshi 1989, 43:52-57.

4. Gyori $E_{1}$ Hyma BA: Fatal automobile crash caused by cerebral toxoplasmosis. Am J Forensic Med Pathol 1998, 19:178-180. 
5. Flegr J, Havlícek J, Kodym P, Malý M, Smahel Z: Increased risk of traffic accidents in subjects with latent toxoplasmosis: a retrospective casecontrol study. BMC Infect Dis 2002, 2:11.

6. Yereli K, Balcioğlu IC, Ozbilgin A: Is Toxoplasma gondii a potential risk for traffic accidents in Turkey? Forensic Sci Int 2006, 163:34-37.

7. Kocazeybek B, Oner YA, Turksoy R, Babur C, Cakan H, Sahip N, Unal A, Ozaslan A, Kilic S, Saribas S, Aslan M, Taylan A, Koc S, Dirican A, Uner HB, Oz V, Ertekin C, Kucukbasmaci O, Torun MM: Higher prevalence of toxoplasmosis in victims of traffic accidents suggest increased risk of traffic accident in Toxoplasma-infected inhabitants of Istanbul and its suburbs. Forensic Sci Int 2009, 187:103-108.

8. Flegr J, Klose J, Novotná M, Berenreitterová M, Havlícek J: Increased incidence of traffic accidents in Toxoplasma-infected military drivers and protective effect $\mathrm{RhD}$ molecule revealed by a large-scale prospective cohort study. BMC Infect Dis 2009, 9:72.

9. Alvarado-Esquivel C, Liesenfeld O, Torres-Castorena A, Estrada-Martínez S, Urbina-Alvarez JD, Ramos-de la Rocha M, Márquez-Conde JA, Dubey JP: Seroepidemiology of Toxoplasma gondii infection in patients with vision and hearing impairments, cancer, HIV, or undergoing hemodialysis in Durango, Mexico. J Parasitol 2010, 96:505-508.

10. Alvarado-Esquivel C, Torres-Berumen JL, Estrada-Martinez S, Liesenfeld O Mercado-Suarez MF: Toxoplasma gondii infection and liver disease: a case-control study in a Northern Mexican population. Parasit Vectors 2011, 4:75.

11. Vyas A, Kim SK, Giacomini N, Boothroyd JC, Sapolsky RM: Behavioral changes induced by Toxoplasma infection of rodents are highly specific to aversion of cat odors. Proc Natl Acad Sci USA 2007, 104:6442-6447.

12. Fekadu A, Shibre T, Cleare AJ: Toxoplasmosis as a cause for behaviour disorders-overview of evidence and mechanisms. Folia Parasitol (Praha) 2010, 57:105-113.

13. Schlottmann A, Kleemann D, Kranz K, Schmal G: Sudden deafness and increased toxoplasmosis IgM titer. Laryngorhinootologie 1996, 75:687-690.

14. Alvarado-Esquivel C, Estrada-Martínez S, García-López CR, Rojas-Rivera A, Sifuentes-Álvarez A, Liesenfeld O: Seroepidemiology of Toxoplasma gondii infection in Tepehuanos in Durango, Mexico. Vector Borne Zoonotic Dis 2012.

15. Alvarado-Esquivel C, Estrada-Martínez S, Liesenfeld O: Toxoplasma gondii infection in workers occupationally exposed to unwashed raw fruits and vegetables: a case control seroprevalence study. Parasit Vectors 2011, $4: 235$

16. Alvarado-Esquivel C, Liesenfeld O, Márquez-Conde JA, Estrada-Martínez S, Dubey JP: Seroepidemiology of infection with Toxoplasma gondii in workers occupationally exposed to water, sewage, and soil in Durango, Mexico. J Parasitol 2010, 96:847-850.

17. Alvarado-Esquivel C, Torres-Castorena A, Liesenfeld O, García-López C Estrada-Martínez S, Sifuentes-Álvarez A, Marsal-Hernández J, Esquivel-Cruz R, Castañeda A, Dubey JP: Seroepidemiology of Toxoplasma gondii infection in pregnant women in rural Durango, Mexico. J Parasitol 2009, 95:271-274.

18. Havlícek J, Gasová ZG, Smith AP, Zvára K, Flegr J: Decrease of psychomotor performance in subjects with latent 'asymptomatic' toxoplasmosis. Parasitology 2001, 122:515-520

19. Novotná M, Havlícek J, Smith AP, Kolbeková P, Skallová A, Klose J, Gasová Z, Písacka M, Sechovská M, Flegr J: Toxoplasma and reaction time: role of toxoplasmosis in the origin, preservation and geographical distribution of Rh blood group polymorphism. Parasitology 2008, 135:1253-1261.

20. Flegr J, Novotná M, Lindová J, Havlícek J: Neurophysiological effect of the $\mathrm{Rh}$ factor. Protective role of the RhD molecule against Toxoplasmainduced impairment of reaction times in women. Neuro Endocrinol Lett 2008, 29:475-481.

21. Webster JP, McConkey GA: Toxoplasma gondii-altered host behaviour: clues as to mechanism of action. Folia Parasitol (Praha) 2010, 57:95-104.

22. Alvarado-Esquivel C, Urbina-Álvarez JD, Estrada-Martínez S, TorresCastorena A, Molotla-de-León G, Liesenfeld O, Dubey JP: Toxoplasma gondii infection and schizophrenia: A case control study in a low Toxoplasma seroprevalence Mexican population. Parasitol Int 2011, 60:151-155.

23. Alvarado-Esquivel C, Estrada-Martínez S, Pizarro-Villalobos H, ArceQuiñones M, Liesenfeld O, Dubey JP: Seroepidemiology of Toxoplasma gondii infection in general population in a Northern Mexican City. J Parasitol 2011, 97:40-43.
24. Velasco-Castrejón O, Salvatierra-Izaba B, Valdespino JL, Sedano-Lara AM, Galindo-Virgen S, Magos C, Llausás A, Tapia-Conyer R, Gutiérrez G, Sepúlveda J: Seroepidemiology of toxoplasmosis in Mexico. Salud Publica Mex 1992, 34:222-229.

25. Alvarado-Esquivel C, Sifuentes-Alvarez A, Narro-Duarte SG, EstradaMartinez S, Diaz-Garcia JH, Liesenfeld O, Martinez-Garcia SA, CanalesMolina A: Seroepidemiology of Toxoplasma gondii infection in pregnant women in a public hospital in northern Mexico. BMC Infect Dis 2006, 6:113.

doi:10.1186/1756-3305-5-13

Cite this article as: Alvarado-Esquivel et al: High seroprevalence of Toxoplasma gondii infection in a subset of Mexican patients with work accidents and low socioeconomic status. Parasites \& Vectors 2012 5:13.

\section{Submit your next manuscript to BioMed Central and take full advantage of:}

- Convenient online submission

- Thorough peer review

- No space constraints or color figure charges

- Immediate publication on acceptance

- Inclusion in PubMed, CAS, Scopus and Google Scholar

- Research which is freely available for redistribution

Submit your manuscript at www.biomedcentral.com/submit
C Biomed Central 